\title{
Measuring changes in physical size and predicting weight of sows during gestation
}

\author{
M. K. O'Connell ${ }^{1 \dagger}$, P. B. Lynch ${ }^{1}$, S. Bertholot ${ }^{2}$, F. Verlait ${ }^{2}$ and P. G. Lawlor ${ }^{1}$ \\ ${ }^{1}$ Teagasc Pig Production Development Unit, Moorepark Research Centre, Fermoy Co. Cork, Ireland; ${ }^{2}$ ENITA de Bordeaux, 1 Cours du Général de Gaulle, \\ C540201, 33175 Gradignan Cedex, France
}

(Received 2 March 2007; Accepted 21 June 2007)

\begin{abstract}
Changes in physical body size during gestation were monitored using 529 sets of sow measurements. All sows were from the same herd and production system with a range in parity from 1 to 8 . Sows were individually weighed, P2 backfat thickness was determined by ultrasound and morphometric measurements of body size were taken five times during gestation: day 0 (at service), day 25, day 50, day 80 and day 110. The morphometric measurements included sow height (from floor to last rib at the midline, from floor to ventral surface and from floor to hip), heart girth, depth of last rib, length (from snout to tail and from anterior scapula to tail) and width (at ham, at last rib and at shoulder). Regression analyses were used to model the relationship between day of gestation or parity number and morphometric measurements of body size. Regression equations were also developed to estimate sow weight from physical measurements, day of gestation and parity. As expected, sow dimensions, in general, increased as pregnancy progressed and also with increasing parity number. The relationships between day of gestation and body dimensions were described by linear and quadratic regression models, which had a range of adjusted $\mathrm{R}^{2}$ values up to 0.99 . Similar relationships to parity number had a range of $\mathrm{R}^{2}$ values between 0.51 and 0.96 . Sow depth, which can be used as an estimate of the width of the sow when lying, equalled the maximum width of the gestation stall $(650 \mathrm{~mm})$ at day 103 of gestation. However, by day 40 of gestation, predicted mean sow depth (570 mm) equalled the width at the rear of the crate. The implication of this is that after day 40 of gestation, the average sow was too wide for the rear of the crate when lying in a recumbent position. On day 110 of gestation, 95\% of the mean sow body depths would be accommodated in stalls that were $674 \mathrm{~mm}$ wide; however, the range in body sizes with increasing parity number suggests the use of more than one stall width would be appropriate. Sow weight could be estimated with an adjusted $\mathrm{R}^{2}$ value of 0.81 and with a residual standard deviation (r.s.d.) of $16.5 \mathrm{~kg}$ using heart girth alone, or more accurately using a model with parity, day of gestation, $P 2$ backfat depth and heart girth as the parameters $\left(R^{2}=0.89\right.$, r.s.d. $\left.12.4 \mathrm{~kg}\right)$.
\end{abstract}

Keywords: gestation, morphometry, size, sows, weight

\section{Introduction}

Although sow size and morphometric measurements change during gestation, and with increasing parity number, sows are housed in a common-sized gestation stall throughout. This is currently the case in many units in Ireland, the UK and the USA. Stalls will be banned in the EU post 2013; however, individual stalls may still be used in the early post-weaning and for a short period prior to farrowing (European Communities (Welfare of Calves and Pigs), Regulations 2003). Allometry has previously been used to determine the static space requirements of animals from physical measurements such as body dimensions (Petherick and Baxter, 1981;

${ }^{\dagger}$ E-mail: karen.oconnell@teagasc.ie
Petherick, 1983; Baxter, 1984). Baxter (1984) recommended stall sizes of $2000 \times 600$ to $650 \mathrm{~mm}$, based on the length and weight of sows, although their sows weighed between 100 and $200 \mathrm{~kg}$, and the pen width was designed to prevent the smallest sow from turning around. For a larger sow, this width could have welfare implications. However, there is little recent information on the changing shape and size of gestating sows.

McGlone et al. (2004) described the approximate dimensions of a sample of gestating sows. Their study was conducted on commercial units in the USA using a number of different lines of crossbred commercial maternal-line sows. They found that sows increased in body dimensions up to parity 6 and with advancing pregnancy. They concluded that stall size would need to increase to $724 \mathrm{~mm}$ 
(from a standard commercial size of $580 \mathrm{~mm}$ ) to accommodate the body size of the majority of gestating sows.

The present study follows a design similar to that of McGlone et al. (2004) and its objectives were (1) to document the morphometric measurements of gestating sows, and (2) to model the relationships between day of gestation or parity number on physical dimensions of the sows. This would provide novel data for use in the design of sow housing. It was also envisaged that a simple equation could be developed using easily obtained morphometric measurements to estimate sow weight. This would be useful on commercial units as an aid to determining the nutritional requirements of individual sows where individual weights may not be easily obtained.

\section{Material and methods}

This study was conducted between May and December 2005. The present study follows a design similar to that of McGlone et al. (2004), but it was undertaken with one genetic line and production system, which is representative of the vast majority of Irish sow units. In all, 529 sets of measurements from $F_{1}$ sows (Large White $\times$ Landrace; Hermitage Al and Pedigree Pigs, Kilkenny, Ireland) were taken. Parity number ranged from 1 to 8 , and morphometric measurements, ultrasonic P2 backfat thickness and sow weight were taken on day 0 (service), day 25 , day 50 , day 80 and day 110 of gestation. Sows that were removed from the herd or died before farrowing were removed from the database. The numbers of sets of measurements taken in each parity and on each day of gestation are shown in Table 1. Sows were fed a standard dry sow diet (per kg: $132 \mathrm{~g}$ crude protein, $6.19 \mathrm{~g}$ lysine, $4.9 \mathrm{~g}$ methionine plus cysteine, $4.6 \mathrm{~g}$ threonine, $13.0 \mathrm{MJ}$ digestible energy (DE)). Diets were composed of barley $(893 \mathrm{~g} / \mathrm{kg})$, soya hi-pro $(75.0 \mathrm{~g} / \mathrm{kg})$, soya oil $(10.0 \mathrm{~g} / \mathrm{kg})$, L-lysine $\mathrm{HCl}(0.5 \mathrm{~g} / \mathrm{kg})$, dicalcium phosphate $(5.0 \mathrm{~g} / \mathrm{kg})$, limestone flour $(11.0 \mathrm{~g} / \mathrm{kg})$, salt $(4.0 \mathrm{~g} / \mathrm{kg})$, vitamins and mineral $(1.5 \mathrm{~g} / \mathrm{kg})$ and phytase $500 \mathrm{lU} / \mathrm{g}(0.1 \mathrm{~g} / \mathrm{kg})$. The diet was provided as a liquid feed (water-to-meal ratio 4.3:1 fresh basis) twice daily in equal amounts by a computerised liquid feeding system (Big Dutchman, Vechta, Germany) using feed curves that provided a range of total $D E$ allowances (day 0 to 110) between 3300 and $4950 \mathrm{MJ}$ DE.

Sows were weighed and backfat thickness at P2 (over the last rib, $65 \mathrm{~mm}$ from the dorsal midline) was measured using a Renco Lean Meater ${ }^{\circledR}$ (Renco Corporation, North Minneapolis, MN, USA), which had a range and sensitivity of 4 to $35 \pm 1 \mathrm{~mm}$. Ten morphometric measurements were also taken using a specially modified digital calipers, a ruler and a tape measure at each time point in gestation. The digital calipers were modified by adding $30-\mathrm{cm}$ extensions to the jaws of the instrument to enable an accurate reading to be taken at the widest part of the sow's body. The accuracy of the digital calipers was $\pm(0.02+0.00005 \times L)$, where $L$ was the length from the origin to the given position $(\mathrm{mm})$.
Table 1 Number of sets of measurements taken in each parity and on each day of gestation

\begin{tabular}{lrrr}
\hline \hline Parity & No. & Gestation day & No. \\
\hline 1 & 58 & 0 & 74 \\
2 & 140 & 25 & 78 \\
3 & 117 & 50 & 80 \\
4 & 87 & 80 & 140 \\
5 & 45 & 110 & 157 \\
6 & 46 & & \\
7 & 24 & & \\
8 & 12 & & 529 \\
Total & 529 & & \\
\hline \hline
\end{tabular}

The morphometric and P2 backfat measurements were taken on sows standing in a relaxed state on the level surface of their stalls. Morphometric measures included heart girth, height, depth, length and width. Heart girth was defined as the circumference of the sow immediately behind the front legs and in front of the first mammary glands (Iwasawa et al., 2004). Height was measured from the floor to the dorsal surface at the last rib and to the dorsal surface at the hip. Height from the floor to the ventral surface of the sow, at the last rib, was also measured. Depth of the sow was determined between the dorsal and ventral surfaces, at the last rib. This measurement corresponded to the difference between the distance from the floor to the hip and the height from the floor to the ventral surface. Sow width was measured at the widest part of the ham, the last rib and the shoulder. Sow length was measured when the sow was standing straight and was taken from the tip of the snout to the posterior of the sow. A second measure of sow length was taken from the anterior scapula to the posterior of the sow, which equated to the body length, not including the head. These measurements were similar to those described by McGlone et al. (2004).

Gestation stalls opened with a hinged section to the rear (Figure 1). The stalls measured $2200 \mathrm{~mm}$ from the front to the rear, including the feed trough, which extended $290 \mathrm{~mm}$ into the stall. The feed trough was raised approximately $280 \mathrm{~mm}$ (at the lowest point of curve) above the floor, allowing the sow to rest her snout underneath. The width of the stall was $650 \mathrm{~mm}$ for a distance of $1300 \mathrm{~mm}$ from the front, and $570 \mathrm{~mm}$ for the $900 \mathrm{~mm}$ hinged section at the rear. The lowest horizontal side bar was $220 \mathrm{~mm}$ above the floor, allowing the sow to extend her legs into the next stall, when lying.

Data were analysed using regression procedures in SAS version 9.1 (Statistical Analysis Systems Institute, 2006; SAS Inc., Cary, NC, USA). Simple statistics including the means for each measurement, standard deviation, minimum, maximum and lower and upper $95 \%$ confidence limits of the mean (CLM) were determined using PROC MEANS. PROC GLM was used to determine the adjusted leastsquare means values of morphometric measurements per 
day of gestation and parity, using the Tukey-Kramer adjustment for multiple comparisons. The adjusted leastsquare means values were then used in PROC REG to model the relationship between day of gestation or parity number and sow physical measurements. Linear and quadratic models were developed for each individual parameter. PROC REG was used to predict sow weight from each of the individual measurements. Multiple regression analysis, using stepwise selection, was then used to develop an equation that could accurately predict weight using easily obtainable measurements.

(a)

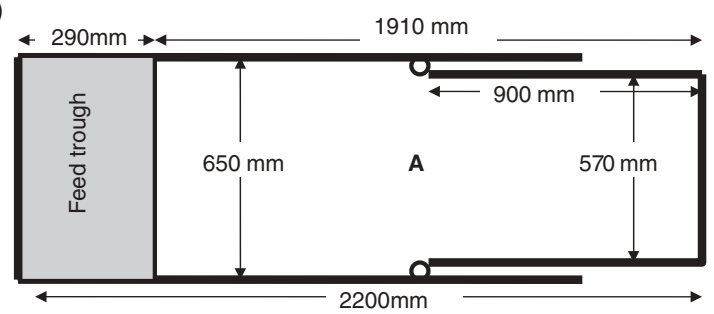

(b)

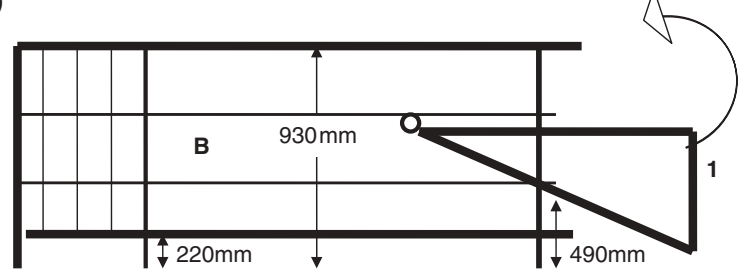

Figure 1 Schematic diagram of gestation crate (not drawn to scale): (a) overhead view; (b) side view. ${ }^{1}$ The rear of the stall consists of a hinged basket-type section, hinged on the inside of the main frame.

\section{Results}

Morphometric measures of gestating sows

Morphometric data are summarised in Table 2. Included are the number of sets of sow measurements, the means, standard deviations, minimum and maximum values observed and the lower and upper 95\% CLM. There was a larger range in heights to dorsal surfaces at the last rib (min. $754 \mathrm{~mm}$, max. $1100 \mathrm{~mm}$, range $346 \mathrm{~mm}$ ) compared with the floor to the dorsal surface at the hip ( $\min .770 \mathrm{~mm}$, max. $1030 \mathrm{~mm}$, range $260 \mathrm{~mm}$ ). However, the mean and lower and upper $95 \%$ CLM of height at the hip were slightly higher than at the last rib $(894,891$ and $897 \mathrm{~mm}$ v. 887, 883 and $890 \mathrm{~mm}$, respectively). Sows were widest at the shoulder (mean $402 \mathrm{~mm}$ ) and ham (mean $395 \mathrm{~mm}$ ), and narrower at the last rib (mean $302 \mathrm{~mm}$ ). Maximum shoulder width was $522 \mathrm{~mm}$ and maximum last rib and ham widths were 490 and $485 \mathrm{~mm}$, respectively.

Mean length from the snout to the posterior of gestating sows was $1807 \mathrm{~mm}$, more than $100 \mathrm{~mm}$ shorter than the stalls (excluding the feed trough). Range in sow lengths (snout to posterior) was between 1560 and $2010 \mathrm{~mm}$ and the lower and upper 95\% CLM were 1800 and $1813 \mathrm{~mm}$, respectively.

\section{Effect of day of gestation on morphometric measures}

Table 3 shows the adjusted least-square means values of all morphometric measurements on each day of gestation. There were no interactions between day of gestation and parity number. Sow measurements generally increased with progression through gestation. Sow body weight increased

Table 2 Morphometric measures of gestating sows ${ }^{t}$

\begin{tabular}{|c|c|c|c|c|c|c|c|}
\hline & $n$ & Mean & s.d. & Min. & Max. & Lower $95 \%$ CLM & Upper 95\% CLM \\
\hline Parity & 529 & 3.4 & 1.8 & 1.0 & 8.0 & 3.3 & 3.6 \\
\hline Weight $(\mathrm{kg})$ & 479 & 237 & 37.8 & 140 & 337 & 233 & 240 \\
\hline P2 backfat thickness (mm) & 529 & 15.7 & 4.4 & 6.5 & 28.0 & 15.3 & 16.0 \\
\hline Heart girth $(\mathrm{mm})$ & 529 & 1397 & 99.0 & 1090 & 1740 & 1389 & 1406 \\
\hline \multicolumn{8}{|l|}{ Height (mm) } \\
\hline Floor to dorsal surface at last rib & 529 & 887 & 45.9 & 754 & 1100 & 883 & 890 \\
\hline Floor to dorsal surface at hip & 529 & 894 & 38.4 & 770 & 1030 & 891 & 897 \\
\hline Floor to ventral surface & 529 & 281 & 57.2 & 125 & 480 & 276 & 286 \\
\hline \multicolumn{8}{|l|}{ Depth (mm) } \\
\hline At last rib, dorsal to ventral surface & 529 & 605 & 59.0 & 462 & 800 & 600 & 610 \\
\hline \multicolumn{8}{|l|}{ Width (mm) } \\
\hline Ham & 425 & 395 & 28.9 & 319 & 485 & 392 & 397 \\
\hline Last rib & 425 & 302 & 55.0 & 198 & 490 & 297 & 307 \\
\hline Shoulder & 425 & 402 & 38.5 & 309 & 522 & 399 & 406 \\
\hline \multicolumn{8}{|l|}{ Length (mm) } \\
\hline Snout to posterior & 527 & 1807 & 76.4 & 1560 & 2010 & 1800 & 1813 \\
\hline Anterior scapula to posterior & 528 & 1241 & 76.5 & 1030 & 1600 & 1235 & 1247 \\
\hline
\end{tabular}

Abbreviations are: s.d. $=$ standard deviation; Min. = minimum; Max. = maximum; CLM $=95 \%$ confidence limits of the mean.

${ }^{+}$Data for all sows (parity 1 to 8 ) across all stages of gestation. 
O'Connell, Lynch, Bertholot, Verlait and Lawlor

Table 3 Adjusted least-square means values of morphometric measurements on each day of gestation ${ }^{+}$

\begin{tabular}{|c|c|c|c|c|c|c|c|}
\hline & \multicolumn{5}{|c|}{ Day of gestation } & \multirow[b]{2}{*}{ s.e. } & \multirow[b]{2}{*}{ Significance } \\
\hline & 0 & 25 & 50 & 80 & 110 & & \\
\hline$n$ & 74 & 78 & 80 & 140 & 157 & & \\
\hline Weight (kg) & 207 & 219 & 237 & 261 & 282 & 2.60 & $* * *$ \\
\hline P2 backfat thickness (mm) & 13.0 & 14.0 & 15.2 & 17.0 & 17.7 & 0.38 & $* * *$ \\
\hline Heart girth $(\mathrm{mm})$ & 1326 & 1347 & 1393 & 1450 & 1485 & 7.5 & *** \\
\hline \multicolumn{8}{|l|}{ Height (mm) } \\
\hline Floor to dorsal surface at last rib & 893 & 882 & 895 & 899 & 894 & 4.0 & 0.14 \\
\hline Floor to dorsal surface at hip & 895 & 894 & 902 & 909 & 901 & 3.3 & * \\
\hline Floor to ventral surface & 333 & 332 & 309 & 282 & 228 & 4.1 & $* * *$ \\
\hline \multicolumn{8}{|l|}{ Depth (mm) } \\
\hline At last rib, dorsal to ventral surface & 560 & 551 & 585 & 617 & 667 & 3.9 & $* * *$ \\
\hline \multicolumn{8}{|l|}{ Width (mm) } \\
\hline Ham & 374 & 387 & 398 & 410 & 410 & 2.6 & *** \\
\hline Last rib & 226 & 251 & 291 & 334 & 336 & 3.7 & $* * *$ \\
\hline Shoulder & 374 & 388 & 405 & 423 & 426 & 3.5 & *** \\
\hline \multicolumn{8}{|l|}{ Length (mm) } \\
\hline Snout to posterior & 1804 & 1805 & 1816 & 1830 & 1844 & 6.1 & $* * *$ \\
\hline Anterior scapula to posterior & 1201 & 1217 & 1249 & 1272 & 1279 & 6.7 & $* * *$ \\
\hline
\end{tabular}

${ }^{\dagger}$ Data are the average across parities 1 to 8 .

${ }^{*} P<0.05,{ }^{* * *} P<0.001$.

from $207 \mathrm{~kg}$ at service to $282 \mathrm{~kg}$ at day 110 of gestation $(P<0.001)$. P2 backfat thickness and heart girth also increased, from 13.0 to $17.7 \mathrm{~mm}(P<0.001)$ and from 1326 to $1485 \mathrm{~mm}(P<0.001)$, respectively, between day 0 and 110. Height from the floor to the dorsal surface at the hip was significantly affected by day of gestation $(P<0.05)$. The relationship was described by the regression models, although not accurately $(P>0.05)$. Height from the floor to the ventral surface of the sow at the last rib decreased as pregnancy progressed, from 333 to $228 \mathrm{~mm}(P<0.001)$. This is due to an increase in the depth of sow between the dorsal and ventral surfaces at the last rib, from 560 to $667 \mathrm{~mm}(P<0.001)$. Sow width increased at the ham (374 to $410 \mathrm{~mm} ; P<0.001$ ), at the last rib (226 to $336 \mathrm{~mm}$, $P<0.001)$ and at the shoulder with day of gestation (374 to $426 \mathrm{~mm} ; P<0.001$ ). Sows also increased in length, both from the snout to the posterior $(1804$ to $1844 \mathrm{~mm}$; $P<0.001)$ and from the anterior scapula to the posterior during gestation (1201 to $1279 \mathrm{~mm} ; P<0.001$ ).

\section{Effect of parity on morphometric measures}

Table 4 shows the least-square means of morphometric measurements in each parity. Parity number had a significant effect on all parameters except for width at the last rib. Sow body weight increased from 211 to $267 \mathrm{~kg}$ from parity 1 to $8(P<0.001)$. Although there was a significant influence of parity on $P 2$ backfat thickness $(P<0.001)$, the nature of this effect was unclear. Heart girth increased with parity from 1342 to $1467 \mathrm{~mm}(P<0.001)$ and ham width increased from 383 to $416 \mathrm{~mm}$ for parities 1 to 8 $(P<0.001)$.

Height from the floor to the dorsal surface at the last rib and height from the floor to the dorsal surface at the hip generally increased up to at least parity $7(P<0.001)$. However, although significantly different between parities $(P<0.05)$, the relationship between parity and height from the floor to the ventral surface could not be described by either the linear or the quadratic models $(P>0.05)$. Depth of the sow at the last rib increased with increasing parity number $(P<0.001)$.

Ham width and shoulder width both increased as sows got older (383 to $403 \mathrm{~mm}$ and 396 to $419 \mathrm{~mm}$, respectively; $P<0.001)$. Length from the snout to the posterior (1717 to $1892 \mathrm{~mm} ; P<0.001)$ and from the anterior scapula to the posterior $(1179$ to $1292 \mathrm{~mm} ; P<0.001)$ both increased with parity.

Best-fit models relating morphometric measurements to day of gestation and parity

Tables 5 and 6 , show the regression coefficients (with standard errors of estimates), $P$-values, adjusted $R^{2}$ and residual standard deviation (r.s.d.) relating change in weight, P2 backfat thickness and morphometric measurements with day of gestation or parity number. Linear and quadratic models were applied to all parameters, and the best-fit models are presented. All except the models relating height 
Table 4 Adjusted least squares means values of morphometric measurements in each parity ${ }^{\dagger}$

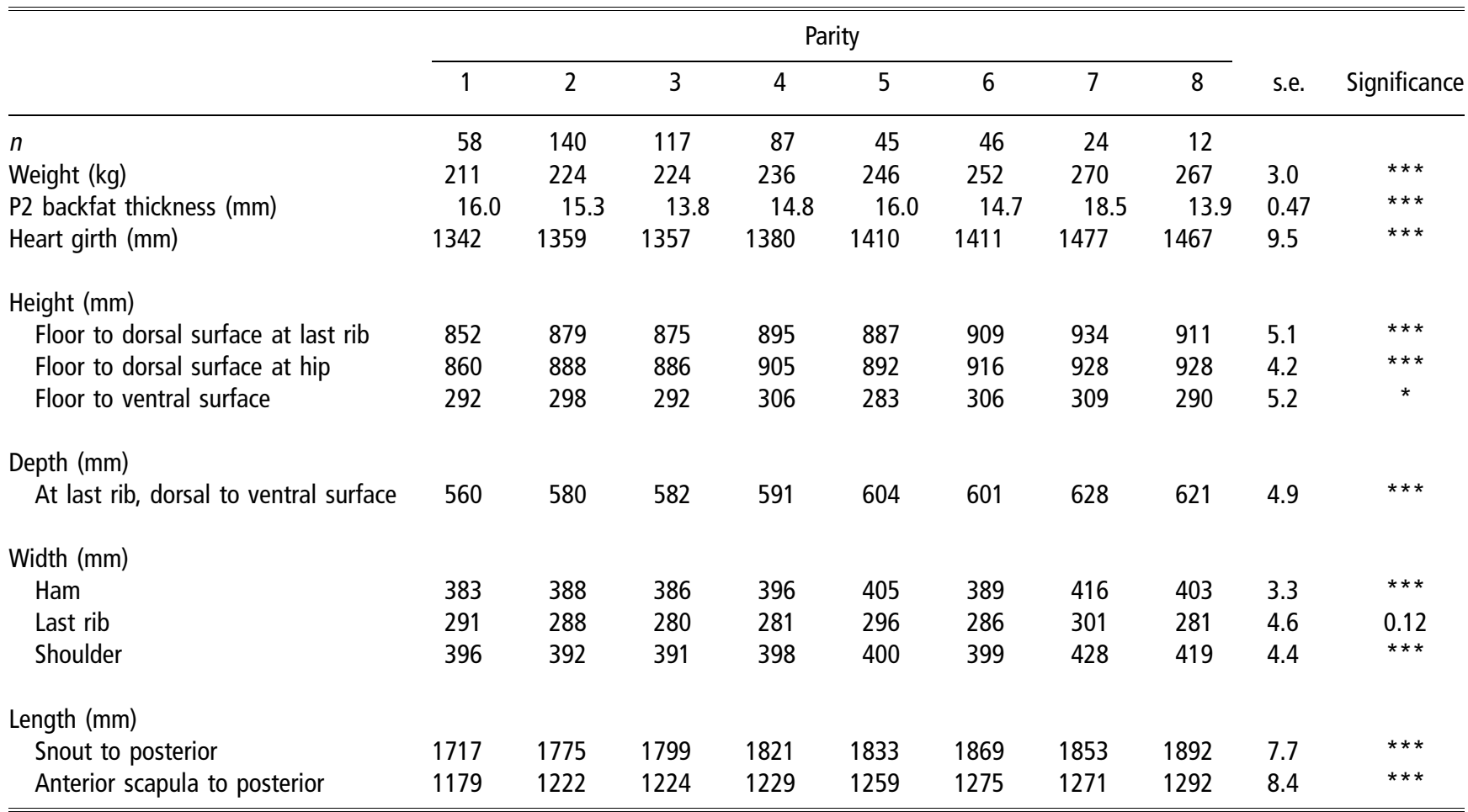

${ }^{\dagger}$ Data are the average across stages of gestation.

${ }^{*} P<0.05,{ }^{* *} P<0.001$.

Table 5 Linear $(y=a+b x)$ and quadratic $\left(y=a+b x+\mathrm{cx}^{2}\right)$ regression model coefficients (with standard error of estimates), significance, adjusted $\mathrm{R}^{2}$ and residual standard deviations for change in morphometric measurements over gestation ( $\mathrm{x}=$ day of gestation)

\begin{tabular}{|c|c|c|c|c|c|c|}
\hline & \multicolumn{3}{|c|}{ Regression coefficients } & \multirow[b]{2}{*}{ Significance } & \multirow[b]{2}{*}{ Adj. $R^{2}$} & \multirow[b]{2}{*}{ Residual s.d } \\
\hline & $a$ & $b$ & $c$ & & & \\
\hline Weight $(\mathrm{kg})$ & $205.7 \pm 2.1$ & $0.586 \pm 0.091$ & $0.001 \pm 0.0008$ & $* *$ & 0.99 & 2.24 \\
\hline P2 backfat thickness (mm) & $12.95 \pm 0.22$ & $0.046 \pm 0.003$ & - & $* * *$ & 0.98 & 0.29 \\
\hline Heart girth $(\mathrm{mm})$ & $1319.2 \pm 6.8$ & $1.532 \pm 0.104$ & - & *** & 0.98 & 9.06 \\
\hline \multicolumn{7}{|l|}{ Height (mm) } \\
\hline Floor to dorsal surface at last rib & $889.2 \pm 4.7$ & $0.069 \pm 0.716$ & - & 0.40 & -0.02 & 6.23 \\
\hline Floor to dorsal surface at hip & $895.2 \pm 3.7$ & $0.096 \pm 0.057$ & - & 0.19 & 0.32 & 4.93 \\
\hline Floor to ventral surface & $333.4 \pm 3.8$ & $0.062 \pm 0.169$ & $-0.009 \pm 0.001$ & ** & 0.99 & 4.13 \\
\hline \multicolumn{7}{|l|}{ Depth (mm) } \\
\hline At last rib, dorsal to ventral surface & $555.8 \pm 9.0$ & $-0.008 \pm 0.396$ & $0.009 \pm 0.003$ & * & 0.96 & 9.70 \\
\hline \multicolumn{7}{|l|}{ Width (mm) } \\
\hline Ham & $372.9 \pm 2.1$ & $0.682 \pm 0.093$ & $-0.003 \pm 0.001$ & * & 0.98 & 2.27 \\
\hline Last rib & $220.5 \pm 11.1$ & $1.765 \pm 0.486$ & $-0.006 \pm 0.004$ & * & 0.94 & 11.91 \\
\hline Shoulder & $372.0 \pm 3.6$ & $0.839 \pm 0.157$ & $-0.003 \pm 0.001$ & * & 0.97 & 3.84 \\
\hline \multicolumn{7}{|l|}{ Length (mm) } \\
\hline Snout to posterior & $1802.6 \pm 2.6$ & $0.143 \pm 0.112$ & $0.002 \pm 0.001$ & * & 0.98 & 2.75 \\
\hline Anterior scapula to posterior & $1198.0 \pm 6.4$ & $1.170 \pm 0.279$ & $-0.004 \pm 0.002$ & * & 0.96 & 6.83 \\
\hline
\end{tabular}

${ }^{*} P<0.05,{ }^{* *} P<0.01,{ }^{* * *} P<0.001$.

from the floor to the last rib and height from the floor to the hip to the day of gestation and those relating P2 backfat thickness, height from the floor to the ventral surface and width at the last rib to parity number were significant. Adjusted $R^{2}$ values and r.s.d. were generally better for day of gestation compared with parity number. 
O'Connell, Lynch, Bertholot, Verlait and Lawlor

Table 6 Linear $(y=a+b x)$ and quadratic $\left(y=a+b x+\mathrm{cx}^{2}\right)$ regression model coefficients (with standard error of estimates), significance, adjusted $\mathrm{R}^{2}$ and residual standard deviations for change in morphometric measurements with increasing parity $(\mathrm{x}=$ parity number)

\begin{tabular}{|c|c|c|c|c|c|c|}
\hline & \multicolumn{3}{|c|}{ Regression coefficients } & \multirow[b]{2}{*}{ Significance } & \multirow[b]{2}{*}{ Adj. $R^{2}$} & \multirow[b]{2}{*}{ Residual s.d. } \\
\hline & $a$ & $b$ & $c$ & & & \\
\hline Weight $(\mathrm{kg})$ & $202.9 \pm 3.4$ & $8.524 \pm 0.673$ & - & $* * *$ & 0.96 & 4.36 \\
\hline P2 backfat thickness (mm) & $15.1 \pm 1.27$ & $0.062 \pm 0.251$ & - & 0.81 & -0.015 & 1.62 \\
\hline Heart girth $(\mathrm{mm})$ & $1333.4 \pm 21.9$ & $6.601 \pm 11.163$ & $1.458 \pm 1.211$ & ** & 0.90 & 15.69 \\
\hline \multicolumn{7}{|l|}{ Height (mm) } \\
\hline Floor to dorsal surface at last rib & $850.9 \pm 9.3$ & $9.310 \pm 1.849$ & - & $* *$ & 0.78 & 11.98 \\
\hline Floor to dorsal surface at hip & $860.0 \pm 6.9$ & $8.964 \pm 1.376$ & - & $* * *$ & 0.86 & 8.91 \\
\hline Floor to ventral surface & $293 \pm 7.7$ & $0.714 \pm 1.518$ & - & 0.65 & -0.13 & 9.84 \\
\hline \multicolumn{7}{|l|}{ Depth (mm) } \\
\hline At last rib, dorsal to ventral surface & $556.4 \pm 5.3$ & $8.774 \pm 1.050$ & - & $* * *$ & 0.91 & 6.80 \\
\hline \multicolumn{7}{|l|}{ Width (mm) } \\
\hline Ham & $379.8 \pm 6.2$ & $3.548 \pm 1.233$ & - & * & 0.51 & 7.99 \\
\hline Last rib & $286.5 \pm 6.4$ & $0.333 \pm 1.265$ & - & 0.80 & -0.15 & 8.20 \\
\hline Shoulder & $398.4 \pm 10.4$ & $-4.583 \pm 5.322$ & $0.988 \pm 0.577$ & * & 0.68 & 7.48 \\
\hline \multicolumn{7}{|l|}{ Length (mm) } \\
\hline Snout to posterior & $1687.3 \pm 19.3$ & $42.387 \pm 9.851$ & $-2.280 \pm 1.068$ & $* * *$ & 0.94 & 13.85 \\
\hline Anterior scapula to posterior & $1165.4 \pm 15.0$ & $22.387 \pm 7.656$ & $-0.875 \pm 0.830$ & $* * *$ & 0.92 & 10.76 \\
\hline
\end{tabular}

${ }^{*} P<0.05,{ }^{* *} P<0.01,{ }^{* *} P<0.001$.

Table 7 Regression models predict sow body weight $(\mathrm{kg})$ from parity number, day of gestation, $P 2$ backfat depth and morphometric measurements

\begin{tabular}{lccc}
\hline \hline Regression models $^{\dagger}$ & $R^{2}$ & Significance & Residual s.d. \\
\hline $212+7.3$ parity & 0.12 & $* * *$ & 35.5 \\
$197+0.66$ day & 0.45 & $* * *$ & 28.1 \\
$150+5.62$ P2 backfat & 0.41 & $* * *$ & 29.2 \\
$-254+0.35$ heart girth & 0.81 & $* * *$ & 16.5 \\
$-25+0.29$ HFLR & 0.13 & $* * *$ & 35.3 \\
$313-0.27$ HFV & 0.15 & $* * *$ & 35.0 \\
$-135+0.42$ HFH & 0.18 & $* * *$ & 34.3 \\
$-32+0.45$ DLR & 0.46 & $* * *$ & 27.9 \\
$-214+0.25$ LSNP & 0.27 & $* * *$ & 32.4 \\
$-90+0.27$ LSHP & 0.28 & $* * *$ & 32.1 \\
$-136+0.95$ WH & 0.54 & $* * *$ & 24.9 \\
$93+0.48$ WLR & 0.44 & $* * *$ & 27.6 \\
$-43+0.70$ WS & 0.50 & $* * *$ & 26.1 \\
\hline \hline
\end{tabular}

${ }^{+}$day = day of gestation; HFLR = height floor to last rib (dorsal surface), $\mathrm{mm} ; \mathrm{HFV}=$ height floor to ventral surface, $\mathrm{mm} ; \mathrm{HFH}=$ height floor to hip (dorsal surface), $\mathrm{mm} ; \mathrm{DLR}=$ depth of last rib (ventral to dorsal surface), $\mathrm{mm}$; LSNP = length snout to posterior, $\mathrm{mm}$; LSHP = length shoulder to posterior, $\mathrm{mm}$; $\mathrm{WH}=$ width of ham, $\mathrm{mm}$; $\mathrm{WLR}=$ width at last rib, $\mathrm{mm}$; WS $=$ width at shoulder, $\mathrm{mm}$. $* * * P<0.001$.

Adjusted $R^{2}$ values ranged between 0.94 (width at last rib) and 0.99 (weight and height floor to ventral surface) for day of gestation and between 0.51 (width of ham) and 0.96 (weight) for parity. The increase in sow body depth over the course of gestation was quadratic. Depth $=555.8-$ $0.008 \times$ day of gestation $+0.009 \times$ day of gestation ${ }^{2}$,

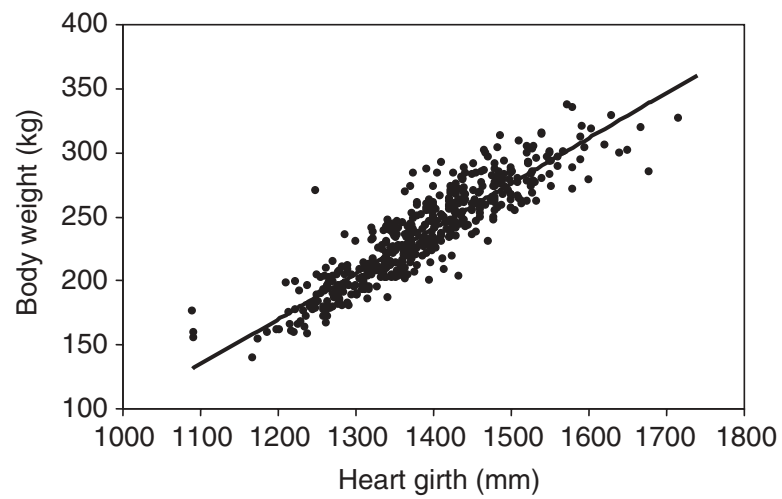

Figure 2 Scatter plot showing relationship between heart girth size and sow body weight. ${ }^{\dagger} Y=-254(10.9)+0.35(0.008) \times X, R^{2}=0.81$, residual standard deviation $=16.5 \mathrm{~kg}, P<0.001$. $^{+}$The points represent the observations $(n=529)$ and the line represents the regression model.

Adj. $R^{2}=0.96$, r.s.d. $=9.70, P<0.05$. The increase in sow body depth with parity was linear. Depth $=556.4+8.774 \times$ parity, Adj. $R^{2}=0.91$, r.s.d. $=6.80, P<0.001$.

\section{Equations to predict sow body weight}

Regression models predicting sow body weight from parity number, day of gestation, P2 backfat thickness and the morphometric measurements taken are presented in Table 7. $R^{2}$ values ranged from 0.12 (parity number) to 0.81 (heart girth) for each of the individual parameters. Figure 2 shows the strong relationship between heart girth and body 
Table 8 Multiple regression models to predict sow body weight $(\mathrm{kg})$ from parity number, day of gestation, P2 backfat depth and morphometric measurements

\begin{tabular}{|c|c|c|c|}
\hline Regression models ${ }^{\dagger}$ : weight $=$ & Adj. $R^{2}$ & Significance & $\begin{array}{l}\text { Residual } \\
\text { s.d. }\end{array}$ \\
\hline$-207+0.24$ day +0.31 heart girth & 0.88 & $* * *$ & 12.6 \\
\hline$-133+3.77$ parity +0.32 day $+1.17 \mathrm{P} 2$ backfat +0.23 heart girth & 0.89 & *** & 12.4 \\
\hline$-314+0.27$ day +0.27 heart girth +0.09 LSNP & 0.91 & *** & 11.2 \\
\hline$-334+0.26$ day +0.24 heart girth +0.09 LSNP $+0.19 \mathrm{WH}$ & 0.92 & $* * *$ & 10.5 \\
\hline$-295+1.80$ parity +0.28 day +0.23 heart girth $+0.06 \mathrm{LSNP}+0.20 \mathrm{WH}$ & 0.92 & *** & 10.2 \\
\hline$-274+2.14$ parity +0.29 day +0.77 P2 backfat +0.20 heart girth +0.07 LSNP +0.18 WH & 0.93 & *** & 10.0 \\
\hline$-283+1.86$ parity +0.26 day +0.81 P2 backfat +0.19 heart girth +0.05 DLR +0.07 LSNP +0.19 WH & 0.93 & $* * *$ & 9.8 \\
\hline $\begin{array}{l}-284+1.79 \text { parity }+0.26 \text { day }+0.78 \text { P2 backfat }+0.19 \text { heart girth }+0.05 \text { DLR }+0.05 \text { LSNP }+0.03 \text { LSHP } \\
+0.19 \text { WH }\end{array}$ & 0.93 & *** & 9.7 \\
\hline
\end{tabular}

${ }^{+}$day = day of gestation; DLR = depth of last rib (ventral to dorsal surface), $\mathrm{mm} ; \mathrm{LSNP}=$ length snout to posterior, $\mathrm{mm} ; \mathrm{LSHP}=$ length shoulder to posterior, $\mathrm{mm} ; \mathrm{WH}=$ width of ham, $\mathrm{mm}$.

$* * * P<0.001$

weight; $81 \%$ of the variability in body weight could be predicted from heart girth alone, and r.s.d. was also lowest for heart girth $(16.5 \mathrm{~kg})$.

A number of multiple regression models to improve the accuracy of weight prediction are presented in Table $8 . R^{2}$ values ranged from 0.88 to 0.93 and r.s.d. was reduced from 12.6 to 9.7 by including two to eight variables. Best-fit models are determined by the highest $R^{2}$ and lowest r.s.d. value. However, in a practical situation, ease of parameter measurement must also be considered. Using these criteria it was determined that weight $(\mathrm{kg})=-133+(3.77 \times$ parity number $)+(0.32 \times$ day of gestation $)+(1.17 \times \mathrm{P} 2$ backfat $)+$ $(0.23 \times$ heart girth), was the 'best' model to predict sow body weight $\left(R^{2}=0.89 ; P<0.001 ;\right.$ r.s.d. $\left.=12.4 \mathrm{~kg}\right)$.

\section{Discussion}

The wide range in sow body weight, P2 backfat thickness and morphometric measurements is not surprising considering the parity distribution and stages of gestation ranging from service to five days pre-farrowing. Previous studies have suggested that sows should gain approximately $45 \mathrm{~kg}$ of weight through gestation, $20 \mathrm{~kg}$ for the weight of the placenta and other products of conception and $25 \mathrm{~kg}$ of maternal body weight gain (Verstegen et al., 1987; Noblet et al., 1990; Young et al., 2005). In this study, the average sow weight gain was $75 \mathrm{~kg}$ (or $36 \%$ of body weight) between day 0 and 110. This large increase in sow body weight and size may have a significant influence on the comfort of sows within the stall dimensions. Increasing body weight also influences nutritional requirements, since at least $80 \%$ of the energy requirements during gestation are required for maintenance, which increases with weight (Iwasawa et al., 2004; Young et al., 2005).

Ninety-five percent of mean sow P2 backfat thicknesses were between 15.3 and $16.0 \mathrm{~mm}$. Backfat thickness was estimated to increase by $0.046 \mathrm{~mm} /$ day of gestation, which agrees with previous studies which found increasing backfat with advancing pregnancy (Young et al., 2005). By day 110 , mean P2 backfat thickness was $17.7 \mathrm{~mm}$ (from $13.0 \mathrm{~mm}$ on day 0 ), which is close to the recommendations of Young and Aherne (2005).

P2 backfat thickness ranged between $6.5 \mathrm{~mm}$ and $28 \mathrm{~mm}$. Thin sows are more likely to develop shoulder lesions than fatter sows because they have less of a covering of fat and muscle covering the shoulder (Zurbrigg, 2006). Shoulder lesions can affect the welfare of the sows, reduce feed intake and possibly impact farm economics if sows are culled early from the herd. Young and Aherne (2005) set a target of $19 \mathrm{~mm}$ backfat at farrowing. They suggest that if 16 to $17 \mathrm{~mm}$ backfat were targeted at farrowing, and a sow lost 3 to $4 \mathrm{~mm}$ during lactation, backfat at weaning would be $<13 \mathrm{~mm}$, leading to reduced reproductive performance. Conversely, the same authors suggested that targeting an average backfat of $21 \mathrm{~mm}$ at farrowing would result in a high proportion of sows with 23 to $24 \mathrm{~mm}$, which could result in reduced lactation feed intake and reduced subsequent reproductive performance.

Baxter (1984) suggests that the minimum space for confinement is the maximum static space requirement. This is equivalent to the space occupied by the sow when lying, which he equates to the height or to the width of the sow when standing. The physical dimensions he described for a $200 \mathrm{~kg}$ sow were $1580 \mathrm{~mm}$ in length (from snout to posterior), $914 \mathrm{~mm}$ in height and $345 \mathrm{~mm}$ in breadth (ham width). McGlone et al. (2004) suggested the depth of the sow, excluding her legs, equates to the width occupied when lying, assuming she will put her legs into the adjacent stall when fully recumbent, or underneath her when lying in a sternum position. Their mean sow height was $881 \mathrm{~mm}$ (at hip), body depth was $577 \mathrm{~mm}$, length was $1712 \mathrm{~mm}$ and ham width was $381 \mathrm{~mm}$. Although Baxter's dimensions are estimates and the sow weight was lower than the weights recorded by McGlone et al. (2004) and the current study, it is clear that sows have increased in body length and width (but not height) since Baxter made his recommendations. In the current study, the mean sow weight was $237 \mathrm{~kg}$, with a 
corresponding length, height and width of 1807, 894 and $395 \mathrm{~mm}$, respectively.

The width of the gestation stalls used in the present study was $650 \mathrm{~mm}$ towards the front and $570 \mathrm{~mm}$ towards the rear where the basket hinge was attached to the stall (Figure 1), both of which were wider than the widest sows at those points, when standing. The younger sows were narrower and shorter than their older counterparts, and this could allow them a chance to turn around within the stall. Baxter (1984) recommends that stalls should have a clear internal width of between 600 and $650 \mathrm{~mm}$, with a gap at the bottom of the divisions of $150 \mathrm{~mm}$ to allow leg room for the sows when lying down. The front part of the stalls conform with these suggestions; however, width at the rear is below the recommendations. However, the design of the rear hinged part of the stall is such that it does not necessarily inhibit the sow lying, in that she can lie under the basket (Figure 1). For smaller sows, Baxter (1984) suggests installing a 'bolster' inside the crate to minimise the risk of sows turning around.

The recommendations made by Baxter (1984) for the width of the stall to be between 600 and $650 \mathrm{~mm}$ are based on prevention of turning around by the smallest gilt, which weighed $100 \mathrm{~kg}$. Using the equation $0.135 \mathrm{~W}^{0.33}$ he suggested a stall width of $617 \mathrm{~mm}$. However, in the current study, the minimum weight for a gilt recorded was $140 \mathrm{~kg}$, which equates to a stall width of $690 \mathrm{~mm}$. The lower $95 \%$ CLM was $233 \mathrm{~kg}$ for all sows, which equates to a stall width of $816 \mathrm{~mm}$. If using Baxter's equation for dynamic space requirement, the stall widths currently in use are too narrow, even for the smallest gilt recorded.

More recently, McGlone et al. (2004) found that sow stall size should be increased to at least $724 \mathrm{~mm}$ from $580 \mathrm{~mm}$ to accommodate gestating sows. Based on the upper $95 \%$ CLM of body depth on day 110 in the current study, stall width should be increased to $674 \mathrm{~mm}$. This would accommodate $95 \%$ of sows in a lying position on day 110 . Ideally, this would be the width for the entire length of the stall. However, the design of the stalls used in the current study incorporated a rear basket hinged on the inside of the stall, reducing the width at the rear.

Stall length, excluding feed trough $(290 \mathrm{~mm})$, was $1910 \mathrm{~mm}$, although sow snouts could be positioned underneath the feed trough (which is approximately $280 \mathrm{~mm}$ above the floor level), giving an effective lying length of $2200 \mathrm{~mm}$. Although some sows were longer than the stalls (excluding feed trough), 95\% of mean sow lengths were between 1800 and $1813 \mathrm{~mm}$, which was within the length of the stall. All sows were shorter than the total length of the stall; $n$ order for the sow to have adequate space to move from a lying to a standing posture, the length required is approximately $20 \%$ greater than the sow length (Baxter, 1984). In the current study, in order to accommodate this posture-changing behaviour in a non-injurious manner, the stall length required by the upper 95\% CLM available length would be $2176 \mathrm{~mm}$. All stalls in the current study were adequate in length, at $2200 \mathrm{~mm}$ total length.
Linear and quadratic models were assessed and the best fit of those (when model $P<0.05$ ) was determined by comparison of the adjusted $R^{2}$ and the residual standard deviation of the models. Not all body measurements or dimensions changed at the same rate during gestation. For example, width at the last rib increased by $55 \%$ from day 0 to day 110 of gestation, while sow length from the snout to the posterior increased by only $2 \%$ over the same period. Growing pigs have also been shown to have different rates of change for different body parts (Doeschl-Wilson et al., 2004). Using the equation relating sow depth and day of gestation, mean sow depth equalled maximum crate width $(650 \mathrm{~mm})$ at day 103 of gestation. However, mean sow depth equalled the width at the rear of the crate by day 40 of gestation $(570 \mathrm{~mm})$. The legislation states that sows and gilts will have to be housed in groups from 4 weeks after service to 1 week prior to the expected farrowing date (European Commission (Welfare of Calves and Pigs), Regulations 2003). For those weeks post service and prefarrowing, they may be accommodated in stalls. The results of this study indicate that the stall sizes may need to be increased slightly from those currently in use in order to avoid negative welfare effects, especially in the late gestation period. Harris et al. (2006) studied the effects of stall or small group gestation housing on the production, health and behaviour of gilts and found that there were relatively few differences between the two housing systems. They did note, however, that the stalls were relatively large $(2.21 \times 0.61 \mathrm{~m})$, considering they had used gilts and felt that this may have influenced the results. If gilts only had been used in the current study, the conclusion may be that the stalls were more than adequate in width; however, the results indicate that for the larger sows, a slightly larger stall would be more appropriate. Further study on the impact of these stall sizes on older, larger sows needs to be conducted.

Studies have shown that there is a higher likelihood for increased total injury scores with increasing body weight for stall-housed sows compared with group-housed sows due to the relative increase in sow size compared with stall size (Anil et al., 2002 and 2003). Injuries to the top of the back are common in stall-housed sows as the back of the sow is pressed forcefully against the bars on the sides of the stall during lateral recumbency because of inadequate width in relation to height of the sow.

The regression models indicate that all morphometric measurements, along with weight and heart girth, increase with increase in parity number, which agrees with the findings of McGlone et al. (2004). As with the day of gestation, the rate of increase was not the same for all measurements. For example, sow height from the floor to the dorsal surface at the last rib and at the hip increased by 9.31 and $8.96 \mathrm{~mm}$ per parity, respectively, while width at the ham increased by $3.55 \mathrm{~mm}$ per parity.

The range in regression coefficients for the simple regression equations indicates the variability in reliability of using different measurements to predict sow weight. Heart 
girth was the best individual predictor of weight; $81 \%$ of the variation in sow body weight could be accounted for by change in heart girth size alone. Iwasawa et al. (2004) developed an equation relating heart girth to sow body weight with a residual of $13.9 \mathrm{~kg}$, which was similar to our residual of $16.5 \mathrm{~kg}$ for the same parameter.

Although it increased with advancing pregnancy and could be accurately predicted from the day of gestation, P2 backfat depth on its own was not a reliable indicator of body weight $\left(R^{2}=0.41\right)$. For practical purposes, using just two measurements, along with parity and day of gestation, up to $89 \%$ of the variability in sow body weight was explained by the following model $\left(R^{2}=0.89 ; P<0.001\right.$; r.s.d. $=12.4 \mathrm{~kg}): \quad$ weight $\quad(\mathrm{kg})=-133+(3.77 \times$ parity number $)+(0.32 \times$ day of gestation $)+(1.17 \times \mathrm{P} 2$ backfat $)+$ ( $0.23 \times$ heart girth).

Although models with higher $R^{2}$ values and lower r.s.d. values were obtained, ease of measurement of parameters was also considered in determining the 'best' practical model. This equation could be useful in a farm situation where often the availability of labour and the time involved in physically moving sows to weighing scales (is available) makes the practice prohibitive. There is also the cost difference between a fibreglass tape measure and weighing scales to be considered.

\section{Conclusions}

Sow size has increased since the recommendations of Baxter (1984). Sow size increased predictably with advancing pregnancy and increase in parity number. By day 40 of gestation, the average sow equalled the width of the rear part of the stall when in a lying position (excluding legs), although sows had the ability to lie underneath the basket part at the rear of the stall. By day 103 of gestation, sow width equalled the maximum width of the stall, leading to possible welfare implications.

There is scope to have more than one size of stall on a unit to accommodate sows in different parities or stages of gestation. Stall design is also important. The stalls used in this study differed in width at the front and rear due to the rear basket hinged on the inside of the stall. A gate-type opening at the rear would allow the stall to be equally wide at the rear and at the front. Further work needs to be conducted into the design of the stall size and how this impacts the welfare of the sow as she increases in size.

Recommendations for stall size depend on the method used to determine optimum stall width. Based on the equation of Baxter (1984), to prevent sows turning, stall width should be increased to $816 \mathrm{~mm}$ to accommodate the lowest $95 \%$ CLM of sow body weights. However, more recently McGlone et al. (2004) based stall size recommendations on sow body depth, which approximates the width of the sow when lying. As gestation progresses, the amount of time spent lying increases. Based on the results obtained here, it can be concluded that for small sows (those in a lower parity number), the current stalls were adequate in size. However, in order to accommodate $95 \%$ of the sows in a lying position in this study (on day 110), stalls would need to measure $674 \mathrm{~mm}$ in width.

The change in various measurements of sow size could be predicted using parity number, and more accurately using day of gestation. Sow girth was the most accurate individual estimator of sow body weight $\left(R^{2}=0.81\right.$, r.s.d. $=16.5 \mathrm{~kg}$ ), but including P2 backfat thickness, parity number and day of gestation improved the estimate further $\left(R^{2}=0.89\right.$, r.s.d. $\left.=12.4 \mathrm{~kg}\right)$.

\section{References}

Anil L, Anil SS and Deen J 2002. Evaluation of the relationship between injuries and size of gestation stalls relative to size of sows. Journal of the American Veterinary Medical Association 221, 834-836.

Anil L, Bhend KMG, Baidoo SK, Morrison R and Deen J 2003. Comparison of injuries in sows housed in gestation stalls $v$. group pens with electronic sow feeders. Journal of the American Veterinary Medical Association 223, 1334-1338.

Baxter S 1984. Space and place. In Intensive pig production: environmental management and design (ed. S Baxter), pp. 210-254. Granada Publishing Ltd, London.

Doeschl-Wilson AB, Whittemore CT, Knap PW and Schofield CP 2004. Using visual image analysis to describe pig growth in terms of size and shape. Animal Science 79, 415-427.

European Community 2003. Welfare of Calves and Pigs, Regulations 2003 (SI No 48 of 2003). Retrieved May 9, 2007, from http://www.irishstatutebook.ie/ ZZSI48Y2003.html

Harris MJ, Pajor EA, Sorrells AD, Eicher SD, Richert BT and Marchant-Forde JN 2006. Effects of stall or small group gestation housing on the production, health and behaviour of gilts. Livestock Science 102, 171-179.

Iwasawa T, Young MG, Keegan TP, Tokach MD, Dritz SS, Goodband RD, DeRouchey JM and Nelssen JL 2004. Comparison of hearth girth or flank-toflank measurements for predicting sow weight. Swine Day 2004 Proceedings, Kansas State University, pp. 17-22.

McGlone JJ, Vines B, Rudine AC and DuBois P 2004. The physical size of gestating sows. Journal of Animal Science 82, 2421-2427.

Noblet J, Dourmad JY and Etienne M 1990. Energy utilization in pregnant and lactating sows: modelling of energy requirements. Journal of Animal Science 68, 562-572.

Petherick JC 1983. A note on allometric relationships in Large White $\times$ Landrace pigs. Animal Production 36, 497-500.

Petherick JC and Baxter SH 1981. Modelling the static spatial requirements of livestock. In Proceedings of the CIGR section II seminar: modelling, design and evaluation of agricultural buildings (ed. JAD MacCormack), pp. 75-82. Scottish Farm Buildings Investigation Unit, Bucksburn, Aberdeen.

Statistical Analysis Systems Institute 2006. User's guide, version 9.1: statistics. SAS Institute Inc., Cary, NC, USA.

Verstegen MWA, Vergahen JMF and Den Hartog LA 1987. Energy requirements of pigs during pregnancy: a review. Livestock Production Science 16, 75-89.

Young $\mathrm{M}$ and Aherne F 2005. Monitoring and maintaining sow condition. Advances in Pork Production 16, 299-313.

Young MG, Tokach MD, Aherne FX, Main RG, Dritz SS, Goodband RD and Nelssen JL 2005. Effect of sow parity and weight at service on target maternal weight and energy for gain in gestation. Journal of Animal Science 83, 255-261.

Zurbrigg K 2006. Sow shoulder lesions: risk factors and treatment effects on an Ontario farm. Journal of Animal Science 84, 2509-2514. 